\title{
Coeruptive and posteruptive crustal deformation associated with the 2018 Kusatsu-Shirane phreatic eruption based on PALSAR-2 time series analysis
}

\author{
Yuji Himematsu ${ }^{1 *}\left(\mathbb{D}\right.$, Taku Ozawa $^{1}$ and Yosuke Aoki
}

\begin{abstract}
Coeruptive deformation helps to interpret physical processes associated with volcanic eruptions. Because phreatic eruptions cause small, localized coeruptive deformation, we sometimes fail to identify plausible deformation signals. Satellite synthetic aperture radar (SAR) data allow us to identify extensive deformation fields with high spatial resolutions. Herein, we report coeruptive crustal deformation associated with the 2018 Kusatsu-Shirane phreatic eruption detected by time series analyses of L-band satellite SAR (ALOS-2/PALSAR-2) data. Cumulative deformation maps derived from SAR time series analyses show that subsidence and eastward displacement dominate the southwestern side of an eruptive crater with a spatial extent of approximately $2 \mathrm{~km}$ in diameter. Although we were unable to identify any significant deformation signals before the 2018 eruption, posteruptive deformation on the southwestern side of the crater has been ongoing until the end of 2019. This prolonged deformation implies the progression of posteruptive physical processes within a confined hydrothermal system, such as volcanic fluid discharge, similar to the processes observed during the 2014 Ontake eruption. Although accumulated snow and dense vegetation hinder the detection of deformation signals on Kusatsu-Shirane volcano using conventional InSAR data, L-band SAR with various temporal baselines allowed us to successfully extract both coeruptive and posteruptive deformation signals. The extracted cumulative deformation is well explained by a combination of normal faulting with a left-lateral slip component along a southwest-dipping fault plane and an isotropic deflation. Based on the geological background in which the shallow hydrothermal system develops across Kusatsu-Shirane volcano, the inferred dislocation plane can be considered as a degassing pathway from the shallow hydrothermal system to the surface due to the phreatic eruption. We reconfirmed that SAR data are a robust tool for detecting coeruptive and posteruptive deformations, which are helpful for understanding shallow physical processes associated with phreatic eruptions at active volcanoes.
\end{abstract}

Keywords: Satellite SAR, Phreatic eruption, Hydrothermal system, Kusatsu-Shirane volcano, Crustal deformation, ALOS-2/PALSAR-2

\section{Introduction}

A phreatic eruption is a hazardous volcanic activity event that includes sporadic ejections of volcanic ash, steam and volcanic gases induced by transient pressure

\footnotetext{
*Correspondence: himematsu@bosai.go.jp

${ }^{1}$ National Research Institute for Earth Science and Disaster Resilience,

Tsukuba, Japan

Full list of author information is available at the end of the article
}

changes in the hydrothermal systems of active volcanoes. These episodic pressure changes are generally induced by injections of volcanic gases into a confined shallow hydrothermal system or by the abrupt boiling of confined overheated geothermal water due to sudden depressurization (Jolly et al. 2014; Narita and Murakami 2018). In general, phreatic eruptions cause 
less damage than magmatic eruptions, but can occasionally produce destructive hazards such as lahars that wash out infrastructure (e.g., Naranjo et al. 1986). An abrupt eruption can be a potential risk to tourists who are visiting volcanoes for mountaineering in the summer and skiing in the winter.

Ground deformation of active volcanoes is usually helpful for interpreting the physical processes of volcanic activity; however, most of ground deformation associated with phreatic eruptions is characterized as small and localized ones with a sudden onset. These characteristics hinder the detection of plausible deformation signals prior to phreatic eruptions due to sparse observation networks or limited measurement accuracy. Recently, satellite synthetic aperture radar (SAR) data have allowed us to identify displacement fields with high spatial resolution without ground-based instruments. Several studies have successfully detected coeruptive deformation associated with phreatic eruptions using satellite SAR data (e.g., Hamling 2017; Doke et al. 2018; Narita and Murakami 2018). If precursors of phreatic eruptions, such as overpressure in shallow hydrothermal systems, persist for a long time, satellite SAR data can identify the precursory deformation signals of a phreatic eruption (Kobayashi et al. 2018).

Kusatsu-Shirane volcano is an active volcanic complex located in central Japan (Fig. 1). It comprises Yugama crater lake, Ainomine volcano, and Moto-Shirane volcano, which are aligned in the north-south direction (Fig. 1). Two subvertical seismicity clusters have been identified 500-2000 m beneath both Yugama crater lake and Ainomine volcano, but not beneath Moto-Shirane volcano (Mori et al. 2006; Japan Meteorological Agency (JMA) 2019). Recent eruptions of Kusatsu-Shirane volcano in 1976, 1982-1983, and 1989 at Yugama crater lake have all been phreatic eruptions (e.g., Ossaka et al. 1980; Ida et al. 1989; Ossaka et al. 1997; Ohba et al. 2008).

The most recent eruption of Kusatsu-Shirane volcano began on January 23, 2018, at 10:02 (Japan Standard Time: JST) at the Kagamiike-kita pyroclastic cone on Moto-Shirane volcano (Fig. 1). This eruption was characterized by an ejection of volcanic ash, steam, and gases. The amount of discharged mass was approximately 30,000-50,000 tons and the eruption plume reached a height of over $5000 \mathrm{~m}$, as observed by a meteorological radar (The joint research team for ash fall in Kusatsushirane 2018 eruption 2018). No plume or gas ejection has been observed since February 22, 2018 (JMA 2018a). Volcanic tremors began 3 min before the phreatic eruption (09:59 JST) and volcanic earthquakes had mostly ceased by March 2018 (JMA 2018b). Airborne SAR images identified a WNW-ESE striking (approximately $\mathrm{N} 105^{\circ} \mathrm{E}-\mathrm{N} 110^{\circ} \mathrm{E}$ ) eruptive crater on the northern part of the Kagamiike-kita pyroclastic cone generated by the 2018 eruption (Geospatial Information Authority of Japan (GSI) 2018). The maximum depth of the crater was greater than $15 \mathrm{~m}$ (The University of Tokyo and Asia Air Survey Co.,LTD 2018). The strike of the eruptive crater was nearly perpendicular to the distribution axis of the pyroclastic cones on Kusatsu-Shirane volcano. The airborne SAR images observations also identified other WNW-ESE striking craters that crossed other pyroclastic cones on Moto-Shirane volcano.

Some research institutes have reported conventional interferometric SAR (InSAR) data for the coeruptive ground deformation associated with the 2018 phreatic eruption (GSI 2018; Meteorological Research Institute 2018). However, some InSAR data were contaminated by decorrelation noises due to variations in the back-scatter characteristics on the ground, such as snow and volcanic tephra coverage. Here, we investigate both the coeruptive and posteruptive deformation signals associated with the 2018 Kusatsu-Shirane phreatic eruption by applying SAR time series analyses to L-band SAR data. We also propose a schematic model that explains the extracted coeruptive deformation.

\section{SAR data processing}

In this study, we employed L-band SAR data acquired from the Phased Array type L-band SAR 2 (PALSAR-2) sensor onboard the Advanced Land Observing Satellite 2 (ALOS-2) to detect crustal deformation signals on Kusatsu-Shirane volcano (Table S1 in Additional file 1). The L-band microwaves (wavelength: $23.6 \mathrm{~cm}$ ) that PALSAR-2 uses are suitable for monitoring deformation signals on volcanoes covered by dense vegetation, such as those in Japan. In general, decorrelation problems can be caused by variations in scattering characteristics on the ground such as snow coverage or dense vegetation. Shorter-wavelength microwaves, such as C-band (wavelength: $5.6 \mathrm{~cm}$ ) and X-band (wavelength: $3.1 \mathrm{~cm}$ ) microwaves, scatter on shallower parts of the snow/ice layer and on leaves or branches. Thus, we expect shorter-wavelength microwaves to suffer from decorrelation problems in this case. In contrast, longer-wavelength microwaves, such as the L-band microwave, can penetrate deeper parts of a snow/ice layer and through dense vegetation. The region around Kusatsu-Shirane volcano is covered by dense vegetation in the summer and by snow in the winter (Figure S1 in Additional file 1).Although the recurrent period of the ALOS-2 satellite (14 days) is greater than that of recent SAR constellations, such as Sentinel-1 (6 days) and Cosmo-SkyMed (1 day at a minimum), coherence using PALSAR-2 data tends to sustain, even with a temporal baseline for the PALSAR-2 InSAR greater than one year. Thus, we expect that the 

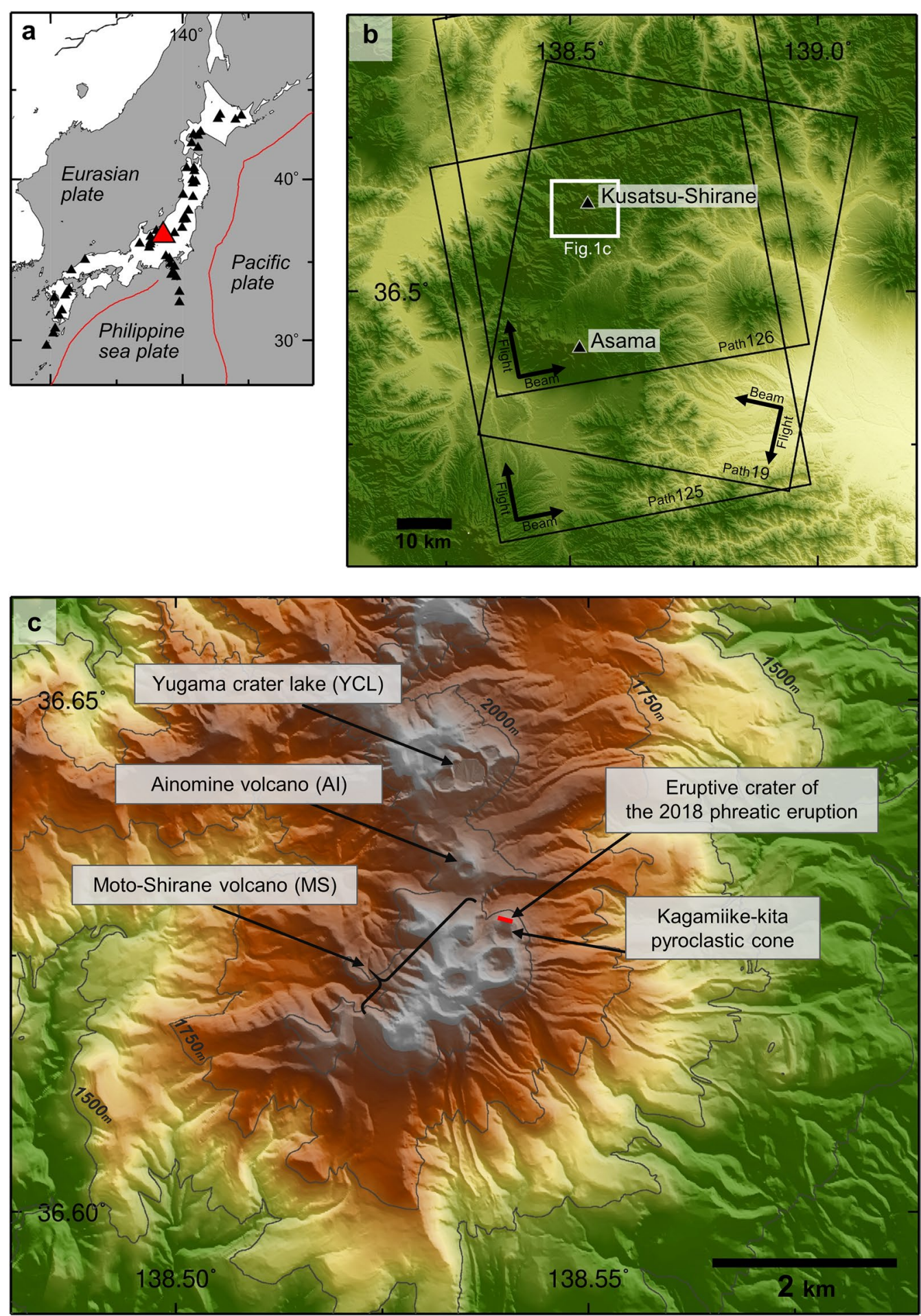

Fig. 1 Map of the study area. a Location of Kusatsu-Shirane volcano (red triangle). Black triangles indicate locations of active volcanoes in Japan. Red lines trace boundaries between tectonic plates. b Location of Kusatsu-Shirane volcano with ALOS-2/PALSAR-2 footprints (black boxes) used in this study. Black arrows indicate satellite flight directions (Flight) and line-of-sight directions (Beam). c Enlarged map of Kusatsu-Shirane volcano 
PALSAR-2 data are suitable for extracting deformation signals around Kusatsu-Shirane volcano through the year.

All InSAR data were generated using the GAMMA software (Wegmüller and Werner 1997). We corrected the topography-dependent fringes using a 10-m mesh digital elevation model released by GSI. Tropospheric artifacts were corrected using zenith tropospheric delays provided by the Generic Atmospheric Correction Online Service for InSAR (GACOS; Yu et al. 2017, 2018). Longwavelength signals across the InSAR data were corrected by fitting $2 \mathrm{D}$ polynomial functions. We discarded some PALSAR-2 data that were contaminated by strong ionospheric artifacts.

We employed a multi-temporal InSAR (MTI) analysis, one of the SAR time series analyses, to infer spatiotemporal variations in the crustal deformation at KusatsuShirane volcano (e.g., Schmidt and Bürgmann 2003). The MTI analysis infers mean displacement rates during each image acquisition interval using the InSAR data with various temporal baselines, assuming constant displacement rates during each image acquisition interval. Figure S2 in Additional file 1 shows a plot of the perpendicular baselines and SAR data combinations for the MTI analysis. We did not set the criteria for spatial and temporal baselines in estimating the displacement time series, unlike the small baseline subset approach (Berardino et al. 2002). One reason for this is that L-band SAR data tend to avoid decorrelation problems even when using a pair of SAR images with a temporal baseline of more than one year. Another reason is that the ALOS-2 satellite has been operating within $500 \mathrm{~m}$ of the perpendicular baseline since the satellite was launched. The Laplacian operators for the smoothing temporal variations in lineof-sight (LOS) changes were optimized using the L-curve criterion (e.g., Hansen 1992; Figure S3 in Additional file 1). We did not infer any temporal variations in the LOS changes for discarded pixels where the coherence of any individual InSAR data point was below 0.1. After estimating the time series of the LOS changes using the MTI analysis, we extracted the cumulative deformation associated with the 2018 phreatic eruption until the end of 2019. Using pairs of cumulative coeruptive LOS changes in paths $19 / 125$ and $19 / 126$, we decomposed them into quasi-east-west (QEW) and quasi-up-down (QUD) components to better understand the spatial characteristics of the coeruptive LOS changes (Fujiwara et al. 2000).

\section{Results}

Coeruptive deformation associated with the 2018 phreatic eruption

Figure 2 shows the cumulative LOS changes in paths 19, 125 , and 126 for approximately two years since the 2018 phreatic eruption. In the path 19 MTI results, a positive
LOS change was dominant on the southwestern side of the 2018 crater. The maximum amplitude of the positive LOS change was $\sim 6 \mathrm{~cm}$ near the 2018 crater. The standard deviation of the inferred displacement velocity in the undeformed region in path 19 was $\sim 1 \mathrm{~cm}$ (Figure S4a in Additional file 1). In the path 19 averaged InSAR data, we identified a displacement discontinuity with a WNWESE strike at the 2018 crater where the path 19 MTI data show missing data (Figure S5 in Additional file 1). The four averaged individual interferograms in path 19 showed the same location for the displacement discontinuity (red arrows in Figure S5a in Additional file 1). Thus, this displacement discontinuity is likely a plausible characteristic of the coeruptive deformation (Table S2 in Additional file 1). The location of the displacement discontinuity is identical to that of the 2018 crater. Unlike the MTI data, the averaged data showed $\sim 5 \mathrm{~cm}$ of negative LOS changes on the northeastern side of the 2018 crater where the path 19 MTI data showed missing data. The negative LOS changes extended $\sim 500 \mathrm{~m}$ to the northeast of the 2018 crater.

The coeruptive deformations from paths 125 and 126 reveal similar characteristics and dominantly positive LOS changes to the southwest of the 2018 crater (Fig. 2b, c). The maximum amplitudes of the positive LOS changes in both paths 125 and 126 were $10 \mathrm{~cm}$ near the 2018 crater, despite a few centimeters of artifacts apparent in the cumulative LOS changes of path 126 . The ascending averaged LOS changes of both paths also failed to detect displacement signals above the 2018 crater, as did the ascending MTI data (Fig. 2b, c; Figures S5b, c in Additional file 1). Standard deviations in paths 125 and 126 are below $1 \mathrm{~cm}$ (Figures S4b, c in Additional file 1).

Next, we decomposed the data into coeruptive QEW and QUD components using the two pairs of cumulative LOS changes in path 19 from the ascending orbit and 125 and 126 from the descending track (Fig. 3). We also plotted the NE-SW cross sections of both QEW and QUD components along profile P-P', which crosses the 2018 crater in a NE-SW direction (Fig. 3e, f). In the QEW components, nearly, the entire region of the displacement fields exhibited eastward movement (Fig. 3a and c). The maximum amplitude of the eastward movement was $\sim 4 \mathrm{~cm}$ near the 2018 crater. Eastward displacements were identified on not only the southwestern side but also the northeast side of the 2018 crater. The two QUD displacement maps show predominantly subsidence on the southwestern side of the 2018 crater and less than $2 \mathrm{~cm}$ of uplift on the northeastern side of the $2018 \mathrm{cra}$ ter (Fig. 3b and d). The cross sections of the coeruptive QUD displacements exhibit an asymmetric pattern with subsidence of up to $\sim 10 \mathrm{~cm}$ near the 2018 crater (Fig. 3f). This asymmetric displacement pattern can be explained 


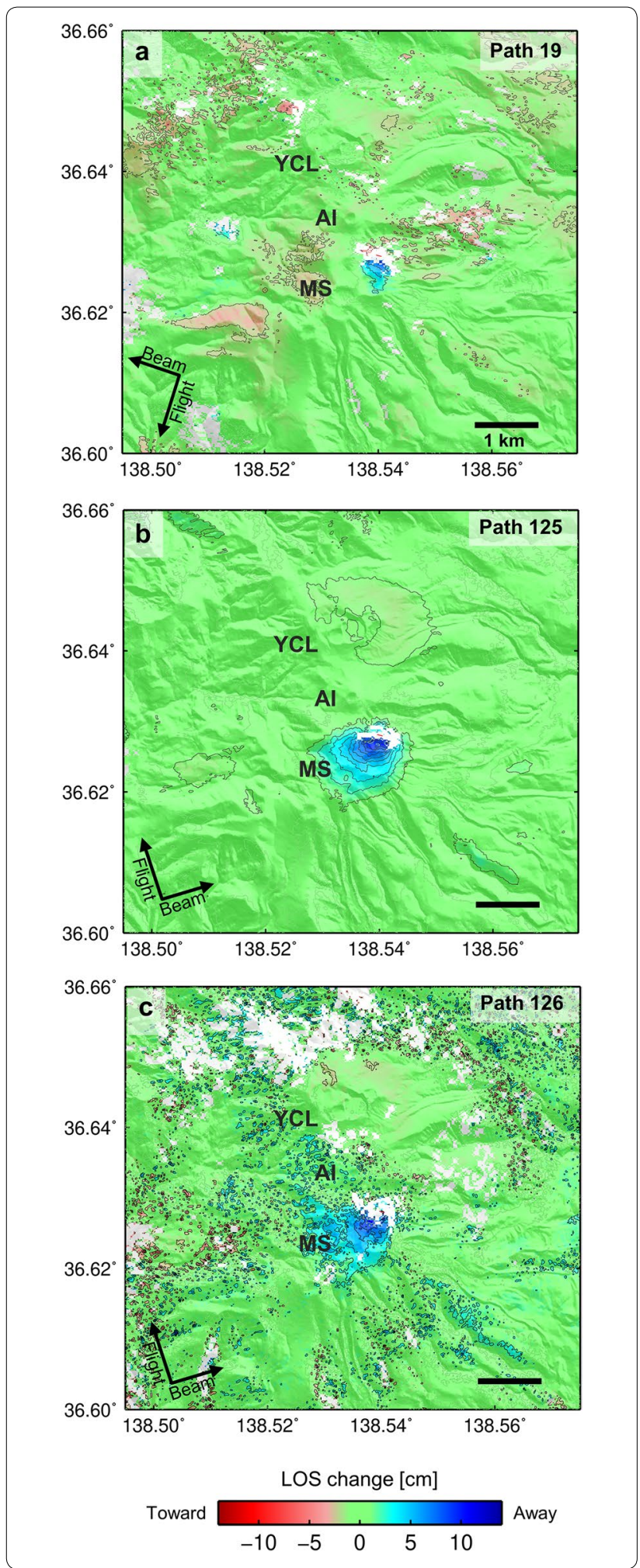

Fig. 2 Cumulative coeruptive deformation associated with the 2018 Kusatsu-Shirane phreatic eruption until the end of 2019. a-c Cumulative line-of-sight (LOS) changes until the end of 2019 from the periods of PALSAR-2 image acquisition prior to the 2018 phreatic eruption. Note that positive LOS changes (blue color) indicate an extension of distance between the satellite and the ground, which means displacement occurs away from the satellite. The satellite flight (Flight) and LOS (Beam) direction are shown in each panel by black arrows. Contours indicate 2-cm LOS change intervals. Gray thick arrows indicate the location of Yugama crater lake. Name of volcanoes are shown: the Yugama crater lake (YCL), Ainomine (Al) and Moto-Shirane volcano (MS)

by a shear dislocation along a plane rather than a point source deflation, which would instead produce a concentric displacement field in the vertical component.

\section{Time series of crustal deformation on Kusatsu-Shirane volcano}

Figure 4 shows the time series of the LOS changes on the southwestern side of the 2018 crater where subsidence with eastward movements was identified in the coeruptive deformation maps. Before the 2018 eruption, the time series of LOS changes in all paths varied within less than $2 \mathrm{~cm}$. Due to the 2018 phreatic eruption, we identified 4 and $7 \mathrm{~cm}$ of positive LOS changes in paths 19 and 126, respectively, until April 2018 (Fig. 4). We also identified the progression of positive LOS changes by the end of 2019; $7 \mathrm{~cm}$ of positive LOS change was indicated in path 19 and $9 \mathrm{~cm}$ of positive LOS change was indicated in path 125. Although there was a temporal gap of more than two years spanning the 2018 eruption in path 125, the path 126 MTI results also shows $\sim 9 \mathrm{~cm}$ of positive LOS change by the end of 2019. The progression of positive LOS change for approximately two years after the 2018 phreatic eruption implies posteruptive deformation, although the amplitudes of the LOS changes are similar to those of other artifacts in individual interferograms. Similar progressive deformation following a phreatic eruption was also observed following the 2014 Ontake (Narita and Murakami 2018) and the 2012 Te Maari eruption (Hamling et al. 2016; Miller et al. 2018).

At Yugama crater lake, the MTI results show that the LOS changes in all paths varied from $1 \mathrm{~cm}$ of positive to $2 \mathrm{~cm}$ of negative LOS changes by the end of 2016 (Figure S6 in Additional file 1). Tiltmeters installed around Yugama crater lake recorded intermittent uplifts at the lake in 2014-2015, 2018, and 2019 (Tokyo Institute of 

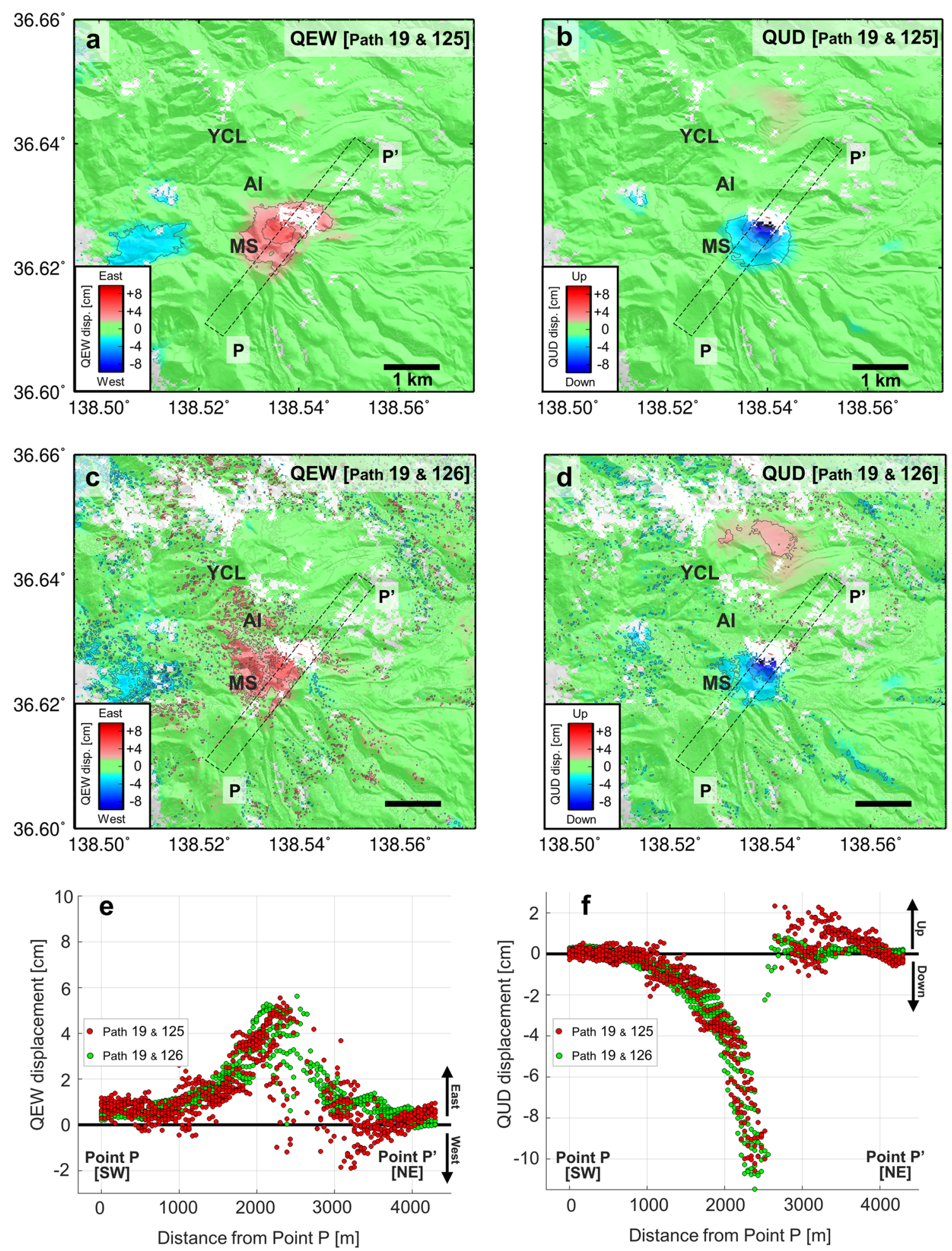

Fig. 3 Quasi-east-west (QEW) and quasi-up-down (QUD) components of the coeruptive deformation. a-d Decomposed QEW and QUD components using pairs of paths 19/125 and 19/126, respectively. Contours indicate $2 \mathrm{~cm}$ intervals of each displacement component. Positive values of QEW and QUD components indicate eastward displacement and uplift, respectively. e, $\mathbf{f}$ Cross sections of QEW and QUD components along the P-P'profile. The profile locations are shown in $(\mathbf{a}-\mathbf{d})$. The plotted dots are the values of each displacement component in pairs of paths $19 / 125$ and 19/126 within the boxes along the P-P'profile 
Technology 2019). The MTI result show $2 \mathrm{~cm}$ of negative LOS change, with a peak in mid-2015, in all paths. This implies the occurrence of uplift, which is also indicated by the tiltmeter observations. Although the tiltmeters detected little vertical movement between 2016 and 2017, variations in positive LOS change were identified, with a maximum magnitude of $2 \mathrm{~cm}$ in path 19. Following the 2018 phreatic eruption, the path 19 MTI results show $2 \mathrm{~cm}$ of uplift with a peak in mid-2018. However, we were unable to identify similar characteristics for the LOS changes in paths 125 and 126 during this period. While we found several differences between the temporal characteristics of the MTI results and those of the tiltmeter observations, the deformation signals in 2014-2019 at Yugama crater lake in all paths appear to have similar spatial extents, which is consistent with a non-vegetated region (Figures S7-S9 in Additional file 1). We presume that the positive LOS changes at Yugama crater lake during 2016-2017 were derived from the residuals of the post InSAR process, or are the result of seasonal variations in soil moisture due to the sparse vegetation around the lake (Gabriel et al. 1989; Zwieback et al. 2015). We have not performed further analysis of the deformation at Yugama crater lake, but future analyses will improve our understanding of the shallow hydrothermal system across Kusatsu-Shirane volcano.

\section{Discussion}

\section{Data fitting of the cumulative LOS changes for the 2018 phreatic eruption}

The PALSAR-2 MTI results allowed us to extract both the deformation signals associated with the 2018 Kusatsu-Shirane phreatic eruption and the time series of LOS changes from 2014-2019 (Figs. 3 and 4). We expect that the spatial characteristics of the coeruptive deformation can be explained by a dislocation along a plane, rather than by volume changes of a point source, because of the observed asymmetry of the coeruptive displacement field. We used the analytical solutions of surface deformation caused by planar dislocation (Model A), volume changes of a point source (Model B), or both (Model C) to fit the observed data (Mogi 1958; Okada 1985). We adopted a grid search algorithm to infer the following best-fit parameters: width, length, dip angle, rake angle, the amount of slip for the planar dislocation and the location, depth, and volume change for the point source. Table S3 in Additional file 1 lists the ranges and intervals of the grid search parameters used in this analysis. We set the top location of the dislocation plane to that of the 2018 eruptive crater, fixed the strike angle at 105 degrees, and set the shallowest depth at $50 \mathrm{~m}$. We regarded the best-fit solution as a combination of parameters that minimized the total root-mean-square (RMS)

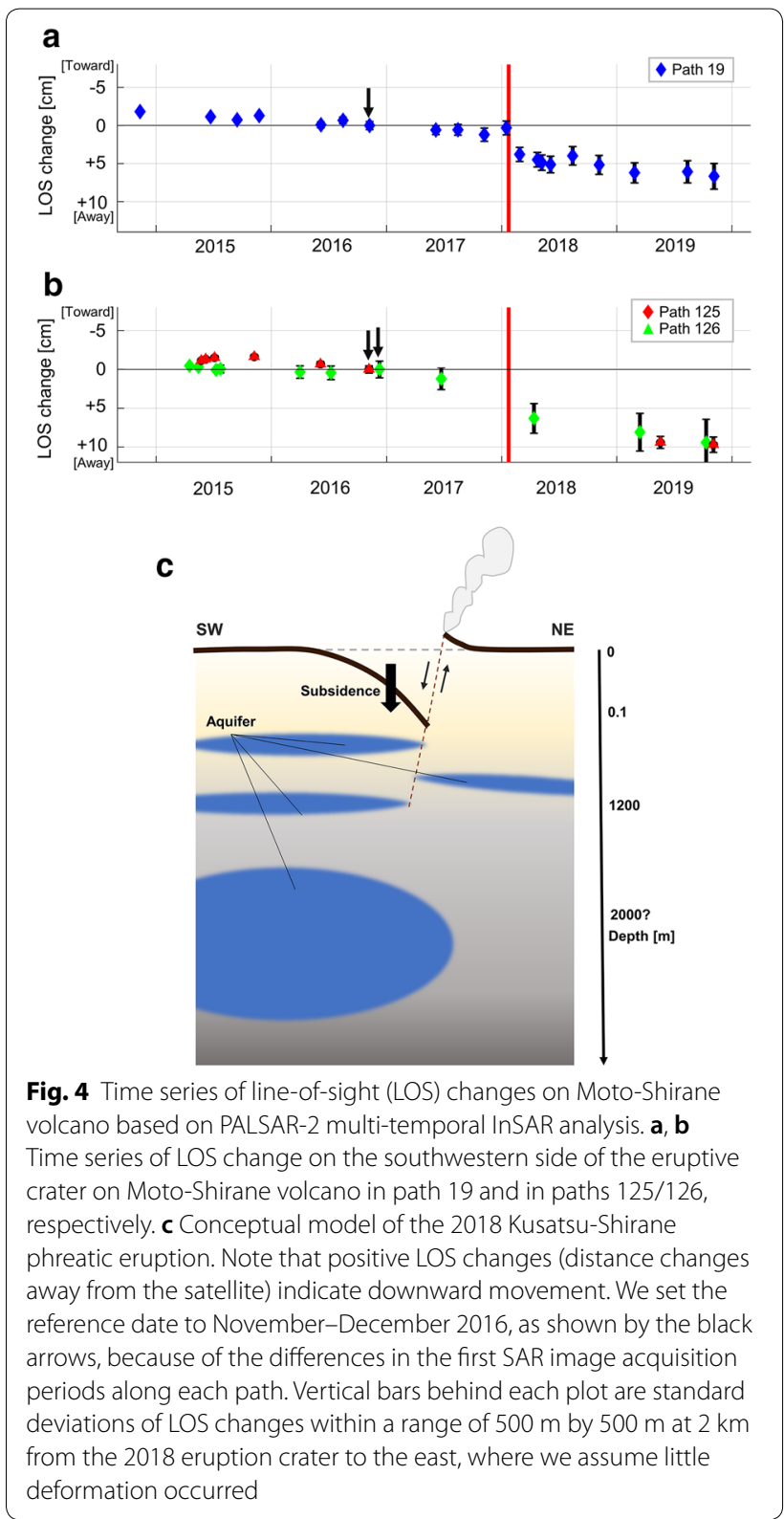

of the residuals between the observed and the computed deformations. We assigned a Poisson's ratio of 0.25. We resampled the LOS change maps in each path using concentric grids (e.g., Fukushima et al. 2005). The 95\% confidence intervals of the best-fit parameters were estimated by a bootstrap approach with 300 iterative nonparametric re-samplings (Efron 1979).

Model C, a combination of a plane dislocation and an isotropic deflation, best fits the observed cumulative deformation associated with the 2018 eruption. It minimizes the total RMS residuals of the observed and computed deformations and exhibits a smaller AIC value 
than other models (Akaike 1974) (Table 1; Figure S10 in Additional file 1). The best-fit geometry of a plane dislocation shows a width of $1500 \mathrm{~m}$, a length of $500 \mathrm{~m}$ and a dip angle of $56^{\circ}$, i.e., the plane extends to the dip direction rather than the horizontal direction and dips toward the southwest. The bottom of the dislocation plane reaches at a depth of greater than $1200 \mathrm{~m}$ from the surface. The best-fit model exhibits a rake angle of -64 degrees and a slip of $0.17 \mathrm{~m}$ on the southwest-dipping plane, which indicates normal faulting with a left-lateral component (Figure S11a in Additional file 1). The total geodetic moment release due to a plane dislocation is $1.3 \times 10^{15}$ $\mathrm{Nm}$, which corresponds to the moment magnitude of 4.0, assuming a shear modulus of $10 \mathrm{GPa}$ (Kanamori 1977). In contrast, the location of the isotropic deflation source was inferred to be located near the eastern edge of the dislocation plane at a depth of $550 \mathrm{~m}$ (Figure S13b in Additional file 1). The best-fit volume change (-30,000 $\mathrm{m}^{3}$ ) of the point source induces approximately $2 \mathrm{~cm}$ of LOS extension at a maximum and up to $0.5 \mathrm{~cm}$ of LOS extension within a $1.5 \mathrm{~km}$ radius. Thus, we can expect that the near-crater deformations were mainly driven by plane dislocation, while wide-range displacements were caused by isotropic deflation. Other single source models (Model A and B) showed greater RMS residuals than those in Model C, while those models indicated similar features for the deformation source parameters as those in Model C (Table 1; Table S4, Figures S12 and S13 in Additional file 1).

\section{Data and model interpretations}

The most plausible interpretation of a plain dislocation dipping from the volcanic crater is a path formation of a sudden steam plume and/or a volcanic gas ejection from the shallow hydrothermal system to the surface. The geometry of the best-fit plane dislocation can be considered as a degassing pathway (Fig. 4c). The best-fit width of the plane in Model C is $1500 \mathrm{~m}$, which indicates that the bottom of the plane reaches an approximately depth of $1200 \mathrm{~m}$. In contrast, the best-fit point source was inferred to be emplaced at the middle part of the eastern edge of the dislocation plane (Figure S10 in Additional file 1). Previous magnetotelluric surveys proposed a lowresistivity subsurface structure from Moto-Shirane volcano to Yugama crater lake at 1500-3000 m below the surface, with alternating thin laminae of low- and highresistivity layers between the surface and large conductor (Nurhasan et al. 2006; Matsunaga et al. 2020). The large conductor implies the emplacement of volcanic fluids that originated from the deep magma source and are confined in a thick impermeable layer. A previous geological survey suggested that the assemblage of ejected materials due to the 2018 eruption likely originated from the basement rock of Moto-Shirane volcano, with an upper location of a few hundred meters below the surface (Yaguchi et al. 2019). Therefore, our model geometry is compatible with the geological observations which imply that the physical processes of the 2018 Kusatsu-Shirane phreatic eruption occurred at a depth of fewer than $1200 \mathrm{~m}$. The best-fit deflation source in our model can be interpreted by depressurization in one of the shallow hydrothermal layers rather than the large low resistivity at the depth of greater than $1500 \mathrm{~m}$.

The increased posteruptive subsidence on the southwestern side of the 2018 crater can be interpreted as the depressurization of the hydrothermal system, mass discharge and thermoelastic compaction (e.g., McTigue 1986; Narita and Murakami 2018). In the 2014 Ontake

Table 1 Best-fit parameters and standard errors for Models A (planar dislocation) and B (point source deflation)

\begin{tabular}{|c|c|c|c|}
\hline & Model A [Plane dislocation] & Model B [Point source deflation] & $\begin{array}{l}\text { Model C [Plane dislocation } \\
\text { and Point source deflation] }\end{array}$ \\
\hline RMS total $[\mathrm{cm}]$ & 1.27 & 1.63 & 1.14 \\
\hline $\mathrm{AIC}$ & 13,509 & 15,297 & 12,429 \\
\hline Slip $[\mathrm{m}]$ & $0.19(0.00)$ & - & $0.17(0.00)$ \\
\hline Width $[\mathrm{m}]$ & $1600(50)$ & - & $1500(75)$ \\
\hline Length [m] & $600(105)$ & - & $500(17)$ \\
\hline Dip [degree] & $52(1.8)$ & - & $56(1.4)$ \\
\hline Rake [degree] & $-68(0.9)$ & - & $-64(0.9)$ \\
\hline Strike [degree] (Fixed) & 105 & - & 105 \\
\hline UTM Easting $[\mathrm{m}]$ & - & $280,000(0.0)$ & $280,250(14)$ \\
\hline UTM Northing [m] & - & $4,056,300(25)$ & $4,056,250(0)$ \\
\hline Depth [m] & - & $300(24)$ & $550(10)$ \\
\hline Volume change $\left[\mathrm{m}^{3}\right]$ & - & $-40,000(6544)$ & $-30,000(1884)$ \\
\hline
\end{tabular}

Standard errors are shown in parentheses 
eruption, a plume from the vent was observed for more than 2 years after the eruption, where the magnitude of posteruptive deformation was at least $30 \mathrm{~cm}$ for 3 years (Narita et al. 2019). For the 2018 Kusatsu-Shirane eruption, steam ejection from the 2018 crater has not been observed since February 22, 2018 and high-frequency earthquakes with volume changes had almost ceased by May 2018 (JMA 2018). Although we cannot currently propose a mechanism for the posteruptive deformation, we do not rule out a contribution from mass discharge as a potential driver of the observed posteruptive deformation. Using the volume change of the point source in our best-fit model, we can quantify $\sim 1.8 \times 10^{7} \mathrm{~kg}$ of the mass discharge due to the source deflation (details are in Text S1 in Additional file 2). The ratio $r_{v}$ of the inferred mass discharge and the ejected volcanic material derived from the rapid field survey ranges from 1.7 to 2.6 (The Joint Research Team for ash fall in Kusatsu-shirane 2018 eruption 2018). The gap can be caused by a compressibility of the cavity and the fluid (Rivalta and Segall 2008; Amoruso and Crescentini 2009). The ratio $r_{v}$ of 1.7-2.6 implies an oblate ellipsoid of the deformation source with the aspect ratio of $0.25-0.35$ between an intermediate and a minor semiaxes. In addition, degassing from the fluid and the well-compliant medium decrease the ratio $r_{v}$ (Amoruso and Crescentini 2009). The rapid field survey reported 30,000-50,000 tons of the ejected volcanic materials associated with the 2018 eruption, while the estimation did not include vaporized water. We also used the volume change of the point source explaining the cumulative eruptive deformation for approximately 2 years since the eruption. Although we should consider those factors to infer the ratio $r_{v}$ accurately, the inferred oblate deformation source does not contradict the alternating (thin) laminae of the low resistivity observed by the previous magnetotelluric survey (e.g., Matsunaga et al. 2020).

The observed asymmetric coeruptive displacement field is similar to the displacement field caused by trapdoor faulting (Amelung et al. 2000; Jónsson et al. 2005). Steep faulting that ruptures from the edge of a horizontal reservoir (aquifer or sill) to the surface can typically explain asymmetric vertical displacements with a hinge due to trapdoor faulting is usually explained by steep faulting that ruptures from the edge of a horizontal reservoir (aquifer or sill) to the surface. Several drivers of trapdoor faulting have been proposed: overpressure due to magma accumulations in a shallow sill and underpressure due to withdrawals of volcanic fluid from a shallow horizontal reservoir. Thus, the polarity of vertical movement depends on the pressure change within the underlying horizontal storage. Trapdoor faulting is typically defined as one end-member of caldera collapse (Acocella 2007).
In contrast, phreatic eruptions can also induce similar asymmetric deformation with a hinge. The 2015 Hakone phreatic eruption (Japan) produced precursor trapdoorlike uplifts driven by overpressure due to the heating of the shallow aquifer (Kobayashi et al. 2018). Kobayashi et al. (2018) propose that the abrupt ejection of volcanic fluid propagated through a steep crack from the shallow aquifer to the surface. In the 2018 Kusatsu-Shirane phreatic eruption, the eruptive craters formed at the northern rim of the Kagamiike-kita pyroclastic cone. Considering that the observed asymmetric-shaped deformation can be interpreted as trapdoor faulting, we can presume the abrupt pressure changes occurred within the aquifer of the peripheral hydrothermal system before and after the phreatic eruption.

Several historical WNW-ESE-aligned craters detected by the GSI airborne SAR images are distributed perpendicular to the distribution axis of the pyroclastic cones on Kusatsu-Shirane volcano (GSI 2018). Although phreatic eruptions are the dominant eruption type, a geological survey suggested that the sequence of pyroclastic cones formed due to magmatic eruptions $\sim 3000$ years ago (Hayakawa and Yui 1989). The orthogonal distribution of small craters and pyroclastic cones may suggest a rotation of the stress regime from a depth at which a magma body is emplaced, to a shallower depth where the hydrothermal system is developed. In addition, the distributions of small craters imply that the physical processes of historical phreatic eruptions were similar to those of the 2018 eruption. The left-lateral component of our best-fit solution can be considered as a stress accommodation in the shallow brittle crust stimulated by breaking seals or weaknesses from normal stress due to episodic degassing. Considering that paths of ejected volcanic fluid usually form along pre-existing fractures or low-energy pathways, the distribution axis of the aligned WNW-ESE craters implies a peripheral stress regime in the shallow part of the crust above the magma source.

\section{Conclusions}

We successfully extracted the coeruptive and posteruptive deformation signals associated with the 2018 Kusatsu-Shirane phreatic eruption based on ALOS-2/ PALSAR-2 MTI data. The PALSAR-2 MTI results show that the coeruptive deformation fields are dominantly characterized by $10 \mathrm{~cm}$ of subsidence and eastward movement on the southwestern side of the 2018 crater, which formed on the northern side of the Kagamiikekita pyroclastic cone. We identified approximately 2-3 cm of posteruptive deformation that lasted for approximately 2 years following the 2018 eruption, while few plausible deformations were observed before the 2018 eruption. A combination of normal faulting 
with a left-lateral slip component on a southwest-dipping plane and an isotropic deflation yield a favorable solution that fits the spatial characteristics of the extracted cumulative deformation associated with the 2018 phreatic eruption. The inferred best-fit dislocation plane can be interpreted as a pathway for volcanic fluid transport from the deformation source to the surface. This interpretation is compatible with the geological background in which the shallow hydrothermal system develops across Kusatsu-Shirane volcano. To our knowledge, this is the first report on crustal deformation associated with the 2018 Kusatsu-Shirane eruption using SAR data.

We reconfirmed that satellite SAR data allow us to detect the high-spatial-resolution crustal deformation on active volcanoes even if the eruption occurs at an unexpected site or in a region with a sparse ground-based network. Although the coeruptive deformation due to the 2018 Kusatsu-Shirane phreatic eruption was small in magnitude $(\sim 10 \mathrm{~cm})$ and in spatial extent $(\sim 2 \mathrm{~km}$ in diameter), similar to deformation caused by other previous phreatic eruptions, the observation data contribute to an understanding of the shallow physical processes related to the 2018 phreatic eruption. Although we only present SAR image processing associated with the 2018 Kusatsu-Shirane eruption in this study, these data will be helpful for supporting other observational dataset.

\section{Supplementary information}

Supplementary information accompanies this paper at https://doi. org/10.1186/s40623-020-01247-6.

Additional file 1. Figure S1.Optical true images of Sentinel-2 data in autumn and winter over Kusatsu-Shirane volcano. Figure S2. Plot of PALSAR-2 perpendicular baselines and combinations of SAR data for the multi-temporal InSAR analyses. Figure S3. L-curve plot for determination of optimal temporal smoothness in the multi-temporal InSAR analysis. Figure S4. Standard deviation of the inferred displacement velocity from 2014-2019. Figure S5. Co-eruptive deformations using the averaging InSAR data spanning the 2018 phreatic eruption. Figure S6. Time series of line-of-sight (LOS) change on Yugama crater lake based on the multi-temporal InSAR analyses. Figure S7. Time-series of PALSAR-2 LOS changes in path 19. Figure S8. Time-series of PALSAR-2 LOS changes in path 125. Figure S9. Time-series of PALSAR-2 LOS change in path 126. Figure S10. Data fitting using analytical solutions of the surface deformation caused by both a plane dislocation and an isotropic deflation (Model C). Figure S11. Root-mean-square error (RMSE) distributions for a plane dislocation and an isotropic deflation in Model C. Figure S12. Data fitting using analytical solutions of the surface deformation caused by a planer dislocation (Model A). Figure S13. Data fitting using analytical solutions of the surface deformation caused by an isotropic deflation (Model B). Table S1. Parameters of PALSAR-2 image acquisition and information for the multi-temporal InSAR analysis in this study. Table S2. Pairs of SAR image acquisition date for the averaged InSAR data in Figure S4. Table S3. Range and interval for the searching best-fit parameters. Table S4. Best-fit RMS residuals of Model A (Planar dislocation) and Model B (Point source deflation) in each path.

Additional file 2: Text S1. Discussion of the discrepancy between the volume change of the point source and the mass discharge.

\section{Abbreviations}

SAR: Synthetic aperture radar; JST: Japan standard time; InSAR: Interferometric SAR; PALSAR-2: Phased Array type L-band SAR 2; ALOS-2: Advanced Land Observing Satellite 2; GSI: Geospatial Information Authority of Japan; MTI: Multi-temporal InSAR; LOS: Line of sight; QEW: Quasi-east-west; QUD: Quasi-up-down.

\section{Acknowledgements}

We would like to thank Dr. Yasuo Ogawa (Editor-in-Chief), Dr. Arthur Jolly (Guest editor) and two anonymous reviewers who reviewed and provided constructive comments to our manuscript. PALSAR-2 level 1.1 data in this study are shared among a PALSAR Interfetometry Consortium to Study our Evolving Land Surface (PIXEL). The data were provided by JAXA under a cooperative research contract with the Earthquake Research Institute, the University of Tokyo. The ownership of PALSAR-2 data belongs to JAXA. This study was made in the framework of subtheme 2-1, Project B of "Integrated program for next generation volcano research and human resource development" led by the Ministry of Education, Culture, Sport, Science and Technology, Japan (MEXT).

\section{Authors' contributions}

YH performed SAR image processing and constructed the model. All authors managed this study, discussed the results. All authors read and approved the final manuscript.

\section{Funding}

This study is funded by "Integrated program for next generation volcano research and human resource development" led by the Ministry of Education, Culture, Sport, Science and Technology, Japan (MEXT).

\section{Availability of data and materials}

ALOS-2/PALSAR-2 level 1.1 data can be searched and purchased from either RESTEC (https://www.restec.or.jp/en/) or PASCO (https://en.alos-pasco.com).

Ethics approval and consent to participate

Not applicable.

\section{Consent for publication}

Not applicable.

\section{Competing interests}

The authors declare that they have no competing interests.

\section{Author details}

${ }^{1}$ National Research Institute for Earth Science and Disaster Resilience, Tsukuba, Japan. ${ }^{2}$ Earthquake Research Institute, The University of Tokyo, Tokyo, Japan.

Received: 20 May 2020 Accepted: 1 August 2020

Published online: 10 August 2020

\section{References}

Acocella V (2007) Understanding caldera structure and development: an overview of analogue models compared to natural calderas. Earth-Sci Rev 85:125-160. https://doi.org/10.1016/j.earscirev.2007.08.004

Akaike H (1974) A new look at the statistical model identification. IEEE Trans Automat Contr 19:716-723. https://doi.org/10.1109/TAC.1974.1100705

Amelung F, Jonsson S, Zebker H, Segall P (2000) Widespread uplift and "trapdoor" faulting on Galapagos volcanoes observed with radar interferometry. Nature 407:993-996. https://doi.org/10.1038/35039604

Amoruso A, Crescentini L (2009) Shape and volume change of pressurized ellipsoidal cavities from deformation and seismic data. J Geophys Res 114:B02210. https://doi.org/10.1029/2008JB005946

Berardino P, Fornaro G, Lanari R, Sansosti E (2002) A new algorithm for surface deformation monitoring based on small baseline differential SAR interferograms. IEEE Trans Geosci Remote Sens 40:2375-2383. https://doi. org/10.1109/TGRS.2002.803792

Doke R, Harada M, Mannen K, Itadera K, Takenaka J (2018) InSAR analysis for detecting the route of hydrothermal fluid to the surface during the 2015 
phreatic eruption of Hakone Volcano, Japan. Earth Planets Space 70:63. https://doi.org/10.1186/s40623-018-0834-4

Efron B (1979) Bootstrap methods: another look at the jackknife. Ann Stat $7: 1-26$

Fujiwara S, Nishimura T, Murakami M, Nakagawa H, Tobita M (2000) 2.5-D surface deformation of M6.1 earthquake near Mt Iwate detected by SAR interferometry. Geophys Res Lett 27:2049-2052. https://doi. org/10.1029/1999GL011291

Fukushima Y, Cayol V, Durand P (2005) Finding realistic dike models from interferometric synthetic aperture radar data: the February 2000 eruption at Piton de la Fournaise. J Geophys Res Solid Earth 110:1-15. https://doi. org/10.1029/2004JB003268

Gabriel AK, Goldstein RM, Zebker HA (1989) Mapping small elevation changes over large areas: differential radar interferometry. J Geophys Res 94:9183-9191. https://doi.org/10.1029/JB094iB07p09183

Geospatial Information Authority of Japan (2018) Report on InSAR analysis on Kusatsu-Shirane volcano, issued in the 140th Coordinating Committee for the Prediction of Volcanic Eruption (CCPVE) (in Japanese). https:// www.data.jma.go.jp/svd/vois/data/tokyo/STOCK/kaisetsu/CCPVE/ shiryo/140/140_01-1-2.pdf. Accessed 18 Jul 2020.

Hamling IJ (2017) Crater lake controls on volcano stability: insights from White Island, New Zealand. Geophys Res Lett 44:11311-11319. https://doi. org/10.1002/2017GL075572

Hamling IJ, Williams CA, Hreinsdõttir S (2016) Depressurization of a hydrothermal system following the August and November 2012 Te Maari eruptions of Tongariro, New Zealand. Geophys Res Lett 43:168-175. https://doi. org/10.1002/2015GL067264

Hansen PC (1992) Analysis of discrete III-posed problems by means of the L-curve. SIAM Rev 34:561-580. https://doi.org/10.1137/1034115

Hayakawa Y, Yui M (1989) Eruptive history of the Kusatsu Shirane Volcano. Quaternary Res 28:1-17 (in Japanese with English abstract)

Ida Y, Osada N, Sawada M, Koyama E, Kagiyama T (1989) Seismological study based on recently installed permanent stations and a small eruptive event on January 6, 1989 at Kusatsu-Shirane volcano. Bull Earthq Res Inst Univ Tokyo 64:325-345 (in Japanese)

Japan Meteorological Agency (2018a) Summary of the volcanic activity on Kusatsu-Shirane volcano, issued in the 141th Coordinating Committee for the Prediction of Volcanic Eruption (CCPVE) (in Japanese). https:// www.data.jma.go.jp/svd/vois/data/tokyo/STOCK/kaisetsu/CCPVE/ shiryo/141/141_02.pdf. Accessed 18 Jul 2020.

Japan Meteorological Agency (2018b) Summary of the volcanic activity on Kusatsu-Shirane volcano, issued in the 142th Coordinating Committee for the Prediction of Volcanic Eruption (CCPVE) (in Japanese). https:// www.data.jma.go.jp/svd/vois/data/tokyo/STOCK/kaisetsu/CCPVE/shiry o/142/142_03.pdf. Accessed 18 Jul 2020.

Japan Meteorological Agency (2019) Summary of the volcanic activity on Kusatsu-Shirane volcano, issued in the 143th Coordinating Committee for the Prediction of Volcanic Eruption (CCPVE) (in Japanese). https:// www.data.jma.go.jp/svd/vois/data/tokyo/STOCK/kaisetsu/CCPVE/shiry o/143/143_03.pdf. Accessed 18 Jul 2020.

Jolly AD, Jousset P, Lyons JJ, Carniel R, Fournier N, Fry B, Miller C (2014) Seismo-acoustic evidence for an avalanche driven phreatic eruption through a beheaded hydrothermal system: an example from the 2012 Tongariro eruption. J Volcanol Geotherm Res 286:331-347. https://doi. org/10.1016/j.jvolgeores.2014.04.007

Jónsson S, Zebker H, Amelung F (2005) On trapdoor faulting at Sierra Negra volcano, Galápagos. J Volcanol Geotherm Res 144:59-71. https://doi. org/10.1016/j.jvolgeores.2004.11.029

Kanamori H (1977) The energy release in great earthquakes. J Geophys Res 82:2981-2987. https://doi.org/10.1029/JB082i020p02981

Kobayashi T, Morishita Y, Munekane H (2018) First detection of precursory ground inflation of a small phreatic eruption by InSAR. Earth Planet Sci Lett 491:244-254. https://doi.org/10.1016/j.epsl.2018.03.041

Matsunaga Y, Kanda W, Takakura S, Koyama T, Saito Z, Seki K, Suzuki A, Kishita T, Kinoshita Y, Ogawa Y (2020) Magmatic hydrothermal system inferred from the resistivity structure of Kusatsu-Shirane Volcano. J Volcanol Geotherm Res 390:106742. https://doi.org/10.1016/j.jvolgeores.2019.106742

McTigue DF (1986) Thermoelastic response of fluid-saturated porous rock. J Geophys Res 91:9533. https://doi.org/10.1029/JB091iB09p09533

Meteorological Research Institute (2018) Report on InSAR analysis on KusatsuShirane volcano using ALOS-2/PALSAR-2 data, issued in the 140th
Coordinating Committee for the Prediction of Volcanic Eruption (CCPVE) (in Japanese). https://www.data.jma.go.jp/svd/vois/data/tokyo/STOCK kaisetsu/CCPVE/shiryo/140/140_01-1-1.pdf. Accessed 18 Jul 2020.

Miller CA, Currenti G, Hamling I, Williams-Jones G (2018) Mass transfer processes in a post eruption hydrothermal system: parameterisation of microgravity changes at Te Maari craters, New Zealand. J Volcanol Geotherm Res 357:39-55. https://doi.org/10.1016/j.jvolgeores.2018.04.005

Mogi K (1958) Relations between the eruptions of various volcanoes and the deformations of the ground surfaces around them. Bull Earthq Res Inst Univ Tokyo 36:99-134

Mori T, Hirabayashi J, Nogami K, Onizawa S (2006) A new seismic observation system at the Kusatsu-Shirane volcano. Bull Volcanol Soc Japan 51:41-47. https://doi.org/10.18940/kazan.51.1_41 (in Japanese with English abstract)

Naranjo JL, Sigurdsson H, Carey SN, Fritz W (1986) Eruption of the Nevado del Ruiz volcano, Colombia, on 13 November 1985: tephra fall and lahars. Science 233:961-963

Narita S, Murakami M (2018) Shallow hydrothermal reservoir inferred from post-eruptive deflation at Ontake Volcano as revealed by PALSAR-2 InSAR. Earth Planets Space 70:191. https://doi.org/10.1186/s40623-018-0966-6

Narita S, Murakami M, Tanaka R (2019) Quantitative relationship between plume emission and multiple deflations after the 2014 phreatic eruption at Ontake volcano, Japan. Earth Planets Space 71:145. https://doi. org/10.1186/s40623-019-1124-5

Nurhasan OY, Ujihara N, Tank SB, Honkura Y, Onizawa S, Mori T, Makino M (2006) Two electrical conductors beneath Kusatsu-Shirane volcano, Japan, imaged by audiomagnetotellurics, and their implications for the hydrothermal system. Earth Planets Space 58:1053-1059. https://doi. org/10.1186/BF03352610

Ohba T, Hirabayashi Jl, Nogami K (2008) Temporal changes in the chemistry of lake water within Yugama Crater, Kusatsu-Shirane Volcano, Japan: Implications for the evolution of the magmatic hydrothermal system. J Volcanol Geotherm Res 178:131-144. https://doi.org/10.1016/j.jvolgeores .2008.06.015

Okada Y (1985) Surface deformation due to shear and tensile faults in a halfspace. Bull Seismol Soc Am 75:1135-1154

Ossaka J, Ozawa T, Nomara T, Ossaka T, Hirabayashi J, Takaesu A, Hayashi T (1980) Variation of chemical compositions in volcanic gases and water at Kusatsu-Shirane Volcano and its activity in 1976. Bull Volcanol 43:207-216. https://doi.org/10.1007/BF02597622

Ossaka J, Ossaka T, Hirabayashi J, Oi T, Ohba T, Nogami K, Kikawada Y, Yamano M, Yui M, Fukuhara H (1997) Volcanic activity of Kusatsu-Shirane volcano, Gunma, and secular change in water quality of crater lake Yugama. Chikyukagaku (Geochem.) 31:119-128 (in Japanese with English abstract)

Rivalta E, Segall P (2008) Magma compressibility and the missing source for some dike intrusions. Geophys Res Lett 35:L04306. https://doi. org/10.1029/2007GL032521

Schmidt DA, Bürgmann R (2003) Time-dependent land uplift and subsidence in the Santa Clara valley, California, from a large interferometric synthetic aperture radar data set. J Geophys Res Solid Earth 108:1-13. https://doi. org/10.1029/2002JB002267

The Joint Research Team for ash fall in Kusatsu-shirane 2018 eruption (2018) Ash fall distribution due to the 2018 Kusatsu-Shirane eruption, issued in the 140th Coordinating Committee for the Prediction of Volcanic Eruption (CCPVE) (in Japanese). https://www.data.jma.go.jp/svd/vois/data/ tokyo/STOCK/kaisetsu/CCPVE/shiryo/140/140_01-1-1.pdf. Accessed 18 Jul 2020.

The University of Tokyo and Asia Air Survey Co.,LTD (2019) Report on precise topographic change around Kusatsu-Shirane (Moto-Shirane) volcano, issued in the 140th Coordinating Committee for the Prediction of Volcanic Eruption (CCPVE) (in Japanese). https://www.data.jma.go.jp/ svd/vois/data/tokyo/STOCK/kaisetsu/CCPVE/shiryo/140/140_01-1-1.pdf. Accessed $18 \mathrm{Jul} 2020$

Tokyo Institute of Technology (2019) Crustal deformation on Kusatsu-Shirane volcano, issued in the 145th Coordinating Committee for the Prediction of Volcanic Eruption (CCPVE) (in Japanese). https://www.data.jma.go.jp/ svd/vois/data/tokyo/STOCK/kaisetsu/CCPVE/shiryo/145/145_01 pdf. Accessed 18 Jul 2020.

Wegmüller U, Werner CL (1997) Gamma SAR processor and interferometry software. In: Proceedings of the 3rd ERS symposium, vol SP-414. ESA,Florence, pp 1686-1692 
Yaguchi M, Ohba T, Numanami N, Kawaguchi R (2019) Constituent mineral and water-soluble components of volcanic ash from the 2018 eruption of mt. Motoshirane of Kusatsu-Shirane Volcano, Japan. J Disaster Res 14:991-995. https://doi.org/10.20965/jdr.2019.p0991

Yu C, Li Z, Penna NT (2018) Interferometric synthetic aperture radar atmospheric correction using a GPS-based iterative tropospheric decomposition model. Remote Sens Environ 204:109-121. https://doi.org/10.1016/j. rse.2017.10.038

Yu C, Penna NT, Li Z (2017) Generation of real-time mode high-resolution water vapor fields from GPS observations. J Geophys Res 122:2008-2025. https://doi.org/10.1002/2016JD025753
Zwieback S, Hensley S, Hajnsek I (2015) Assessment of soil moisture effects on L-band radar interferometry. Remote Sens Environ 164:77-89. https://doi. org/10.1016/j.rse.2015.04.012

\section{Publisher's Note}

Springer Nature remains neutral with regard to jurisdictional claims in published maps and institutional affiliations.

\section{Submit your manuscript to a SpringerOpen ${ }^{\circ}$ journal and benefit from:}

- Convenient online submission

- Rigorous peer review

- Open access: articles freely available online

- High visibility within the field

- Retaining the copyright to your article

Submit your next manuscript at $\boldsymbol{\nabla}$ springeropen.com 